\title{
Saludo del Presidente de SOCHIORL
}

La trayectoria de nuestro Congreso anual, es motivo de legítimo orgullo para todos los otorrinolaringólogos nacionales. Hasta esta edición ha sido un pilar destacado en el desarrollo de la especialidad, principal tribuna para exposición de trabajos científicos, experiencias clínicas de los diferentes grupos de trabajo, así como una gran oportunidad para conocer avances y experiencias de primer nivel por la participación de destacados conferencistas nacionales y extranjeros. En su historia ha cumplido, además, un rol trascendental en el fomento de la amistad y camaradería entre los socios, que siempre ha tenido una muy buena valoración por todos los que han participado en ellos.

Cada año, la mayoría de los otorrinos nacionales reservamos la fecha del Congreso en nuestra agenda, con mucha anticipación, con altas expectativas de asistir a un evento de gran envergadura y calidad, que habitualmente satisface lo que esperábamos obtener de él.

Sin duda que después de 64 ediciones, en que han existido sellos de organización y énfasis diferentes, no podemos desconocer que hemos experimentado un crecimiento constante que hace cada vez más compleja su organización.

Junto con este desarrollo, en el contexto del avance de la especialidad, y de nuestra Sociedad, en forma creciente ha surgido la necesidad de la comunicación e inserción con entidades de otras latitudes que nos permita interactuar con especialistas de otros países, que se enfrentan a realidades diferentes a las nuestras, lo que enriquece nuestro aprendizaje, a la vez que nos da la ocasión de compartir nuestras experiencias contribuyendo al mejor conocimiento de nuestra realidad en otros países.

Así surgió hace algunos años una fructífera relación con la Sociedad Hispano Alemana de Otorrinolaringología, que alberga a especialistas alemanes y españoles que tienen fuertes lazos históricos y académicos. En el año 2001, plantearon, lo que ellos llaman el plan Latinoamérica en Hamburgo, que contó con el apoyo unánime de los congresales. Este plan pretende aumentar el nivel de cooperación con las Sociedades de Latinoamérica, e inaugurar una nueva etapa en las relaciones de Sociedades europeas y latinoamericanas de la especialidad, concepto que creo es muy importante para países de nuestra región, que tradicionalmente no hemos tenido muchas oportunidades, de relacionarnos con nuestros pares de Europa, que nos permita un adecuado conocimiento de los avances que se generan en esa parte del mundo. A partir de este hito la Sociedad Chilena ha tenido una destacada participación en actividades de esta Sociedad en: Fulda el 2003, Lanzarote el 2005 en donde fuimos país invitado y Freiburg el año 2007.

Hoy asistimos al primer evento conjunto, nuestro LXV Congreso Chileno y el I Congreso Extraordinario Hispano Alemán, que se realiza fuera de Europa, lo que presenta un enorme desafío de organización, pero que es una gran oportunidad que me parece que es muy importante dimensionar en todo lo que representa.

日 esfuerzo y generosidad de nuestros amigos españoles y alemanes ha sido muy importante para contribuir al éxito de esta enorme empresa: se contempla la participación de 40 conferencistas españoles y alemanes. Se estima además que asistirán un gran número de participantes de ambos países.

Para ser concordantes con el espíritu del plan Latinoamérica y con nuestro interés de interactuar con otros países vecinos, hemos convocado a conferencistas de Brasil, Perú, Argentina, Colombia, Venezuela y Panamá Además se ha entregado la información del 
Congreso a todas las Sociedades Latinoamericanas, para promover la asistencia de la mayor cantidad de otorrinos de países vecinos.

Agradezco a nombre de todos los socios de la SOCHIORL, el gran esfuerzo desplegado por la organización del evento, presidida por la Dra. Maritza Rahal, la generosidad y apoyo de los directivos de la Sociedad Hispano Alemana, el compromiso y participación de conferencistas invitados, a los investigadores que han enviado número inédito de trabajos, a las empresas que nos auspician, a las instituciones que con su patrocinio nos dan un marco de gran jerarquía: Embajada de Alemania, Embajada de España, Ministerio de Salud, Pontificia Universidad Católica de Chile, Universidad de Chile, Universidad de Concepción e llustre Municipalidad de Pucón.

Pucón nos espera para realizar este Congreso con un entorno de belleza natural que será, sin duda, un marco espectacular para todas las actividades académicas y de camaradería. Espero que tengamos un asistencia récord. La participación de cada uno de ustedes es muy importante para que se cumplan todos los objetivos que nos hemos propuesto al programar este LXV Congreso Chileno y I Congreso Extraordinario Hispano Alemán de Otorrinolaringología.

Dr. David Jofré Pavez

Presidente Sociedad Chilena de Otorrinolaringología, Medicina y Grugía de Cabeza y Cuello 